\title{
PCDD/F formation through precursor condensation in a full scale hazardous waste incinerator
}

Article type: Note

Isabel Vermeulen, Jo Van Caneghem (corresponding author), Carlo Vandecasteele

University of Leuven, Department of Chemical Engineering, ProcESS - Process Engineering for sustainable systems, Willem De Croylaan 46, B-3001 Leuven, Belgium

Tel. +3216322353; Fax +3216322991

e-mail: jo.vancaneghem@cit.kuleuven.be

\begin{abstract}
This paper gives the PCDD/F fingerprint of boiler and fly ash of a full scale hazardous waste incinerator and demonstrates that, when the waste to be incinerated contains high concentrations of PCBs and chlorinated pesticides, heterogeneous precursor condensation is the dominant PCDD/F formation mechanism, rather than de novo synthesis. This is in contrast to full scale municipal solid waste (MSW) incinerators, where de novo synthesis has been shown to be the dominant PCDD/F formation mechanism. This paper agrees with earlier predictions based on numerous lab scale experiments.
\end{abstract}

\section{Keywords}

Incineration, PCDD/F, dioxin, hazardous waste, fingerprint 


\section{Introduction}

Polychlorinated dibenzo-p-dioxins (PCDDs) and polychlorinated dibenzofurans (PCDFs) are a group of 210 congeners, of which 2,3,7,8-tetrachlorodibenzo-p-dioxin is considered the most toxic man-made chemical [1]. PCDD/Fs were never produced intentionally as marketable products, but originate as unwanted byproducts of industrial and thermal processes. Therefore, over the last 20 years, a lot of research has been carried out in order to unravel the formation mechanisms of PCDD/Fs in the post-combustion stages of waste incinerators. Most of this research was performed in lab scale installations, in which the combustion parameters influencing the formation of PCDD/Fs, e.g. temperature and residence time, oxygen excess, chlorine concentration, ash composition (e.g. $\mathrm{Cu}$ and $\mathrm{Fe}$ concentration), can more easily be changed and controlled than in full scale installations. Based on the results of this lab scale research, three PCDD/F formation mechanisms were put forward: (i) homogeneous (gas-gas phase) condensation of precursor molecules, (ii) heterogeneous (gas-solid phase) condensation of precursor molecules and (iii) direct formation from carbon in ash particles, which is called de novo synthesis [2-4]. PCDD/F fingerprints, i.e. graphical representations of the concentration of the different PCDD/F congeners analysed, are distinct for each mechanism. Homogeneous precursor condensation typically yields more PCDFs than PCDDs and strongly favours lower chlorinated homologues [5-8]. In heterogeneous precursor condensation and in de novo synthesis higher chlorinated homologues are favored [7], as the formed PCDDs and PCDFs can for some time remain adsorbed on the solid phase and may hence undergo chlorination before release (“aging”). Heterogeneous precursor condensation typically yields more PCDDs than PCDFs [2], whereas de novo synthesis yields more PCDFs than PCDDs. Table 1 summarizes the main characteristics of the three PCDD/F formation mechanisms discussed. These characteristics are based on the results and conclusions of the references cited. 
Table 1 Comparison of the different PCDD/F formation mechanisms

\begin{tabular}{|l|l|c|l|c|}
\hline $\begin{array}{l}\text { Formation } \\
\text { mechanism }\end{array}$ & $\begin{array}{l}\text { Formation } \\
\text { temperature }{ }^{\circ} \mathrm{C}\end{array}$ & $\begin{array}{l}\text { PCDFs/PCDDs } \\
\text { ratio }\end{array}$ & $\begin{array}{l}\text { (Tetra- } \\
\text { pentaCDD/Fs) / } \\
\text { (hexa-octaCDD/Fs) }\end{array}$ & Ref. \\
\hline $\begin{array}{l}\text { Homogeneous } \\
\text { precursor } \\
\text { condensation }\end{array}$ & $400-800$ & $>1$ & $>1$ & {$[5-8]$} \\
\hline $\begin{array}{l}\text { Heterogeneous } \\
\text { precursor } \\
\text { condensation }\end{array}$ & $200-400$ & $<1$ & $<1$ & {$[2,7]$} \\
\hline $\begin{array}{l}\text { De novo } \\
\text { synthesis }\end{array}$ & $200-400$ & $>1$ & & {$[2-4]$} \\
\hline
\end{tabular}

Moreover, several lab scale experiments showed that, under the applied experimental conditions, PCDD/F formation through homogeneous and heterogeneous precursor condensation is about 100 times faster than formation through de novo synthesis [2-3,9]. PCDD/F fingerprints from actual measurements in real full scale municipal solid waste (MSW) incinerators indicated that de novo synthesis is the dominant formation mechanism [2,10-13]. Huang and Buekens [2] stated that precursor concentrations in the combustion gas of full scale MSW incinerators are much lower than in the previously mentioned lab scale experiments. This explains the dominance of the novo synthesis in real full scale incinerators, but holds, however, only for MSW incinerators.

In some types of industrial waste e.g. automotive shredder residue (ASR) and in hazardous wastes, the concentration of POPs such as PCBs, which can thermally decompose into PCDD/F precursors, may be much higher than in MSW [11,14]. So, in full scale hazardous waste incinerators, the formation of PCDD/Fs by precursor condensation in the flue gas may be more important than in MSW incinerators, and precursor condensation may in principle be the dominant PCDD/F formation mechanism, instead of de novo synthesis. Fingerprints 
corresponding to this situation were, to the best of our knowledge, not reported in the literature.

During a study conducted to draw up PCDD/F mass balances for different types of waste incinerators $[11-12 ; 14]$, we noticed that the PCDD/F fingerprint of boiler and fly ash collected in a rotary kiln incinerating hazardous industrial waste, including PCBs and pesticides, was different from the boiler and fly ash fingerprint of the MSW incinerators under study. The PCDD/F fingerprint of the boiler and fly ash of the hazardous waste incinerator indicated that heterogeneous precursor condensation was the dominant PCDD/F formation mechanism in this installation. To draw conclusions on PCDD/F formation mechanisms in waste incinerators in this study, boiler and fly ash are preferred over other incineration outputs, as they are collected in the boiler or in the electrostatic precipitator (ESP) directly after the boiler, where, because of the presence of ash and gas temperatures of around $300{ }^{\circ} \mathrm{C}$, the PCDD/Fs are most likely formed. Furthermore boiler and fly ash is collected before any flue gas cleaning that may influence the PCDD/F fingerprint takes place.

\section{Materials and methods}

\subsection{Incinerator and waste types}

The installation is a rotary kiln incinerator (RKI), located in Antwerp (North of Belgium) incinerating about 100,000 t/year of hazardous industrial waste at temperatures above 1100 ${ }^{\circ} \mathrm{C}$. The combustion gas flows through a boiler, is subsequently de-dusted in an ESP and is then cleaned in a four-step wet gas washing unit. Before release at the stack, the cleaned gas passes through a fixed activated carbon filter for final PCDD/F removal. The hazardous waste incinerated is rather heterogeneous: it consists of e.g. hospital waste, spilled solvents, hazardous household waste, contaminated soil etc. About $1.5 \%$ of the incinerated waste consists of PCB oils and obsolete chlorinated POP pesticides. 
Fig. 1 gives a schematic overview of the rotary kiln incinerator and indicates the temperature of the combustion gas at each stage.

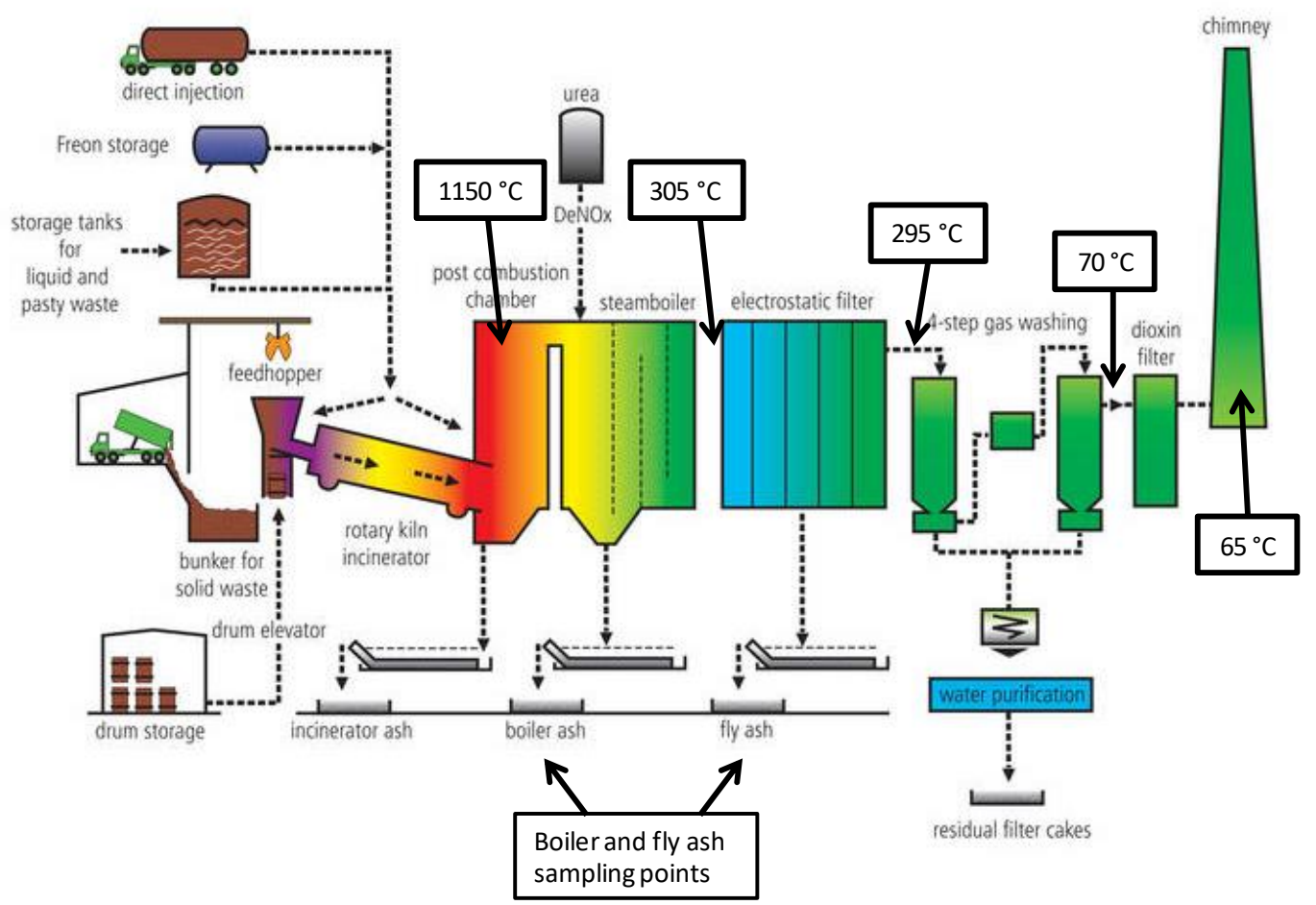

Fig. 1 Schematic overview of the rotary kiln incinerator (RKI) with indication of sampling points and temperatures in post combustion zone

\subsection{Ash sampling and PCDD/F analyses}

The sampling point of the boiler and the fly ash is indicated in Fig. 1 . About $10 \mathrm{~g}$ of boiler and fly ash was sampled three times a day for five consecutive days during normal steadystate operation. Boiler and fly ash are very homogeneous fine powders. At the end of the sampling period, for each ash fraction, all collected samples were mixed thoroughly in a shaking device to give a representative pooled sample. Because of this pooling it was not possible to indicate variation between samples. The sampling was part of a larger study in which also the boiler and fly ash of the GFI discussed in Section 3 and of a fluidised bed combustor were sampled and analysed.. The concentration of the 17 PCDD/F congeners with WHO TEF-values in the pooled ash samples was determined with GC-MS after soxhlet extraction according to the German AbfKlärV, Annex1 [15] 


\subsection{PCDD/F fingerprints and ratios}

The PCDD/F fingerprints reported are a graphical representation of the concentration of each of the $17 \mathrm{PCDD} / \mathrm{F}$ congeners with WHO TEF-values as a percentage of the total PCDD/F concentration of these $17 \mathrm{PCDD} / \mathrm{Fs}$. The considered concentrations are mass concentrations $\left(\right.$ ng.kg $\left.{ }^{-1}\right)$. These were not converted to TEQ by multiplying them with the respective TEF values as this would render the fingerprints no longer representative for the formation mechanisms under study. Results for congeners without TEF value were not obtained, as the measurements framed in another study where only the PCDD/Fs with a TEF value were of interest. Next to the overall PCDF/PCDD-ratio, also a PCDF/PCDD-ratio for moderate (tetrato penta-CDD/Fs) and one for high (hexa- to octa-CDD/Fs) chlorinated homologues is given, as the latter two give information on the homogeneous and the heterogeneous formation mechanisms, respectively.

\section{Results and discussion}

Fig. 2 gives the fingerprint of the boiler and of the fly ash of the considered RKI. Fig. 2 also gives the PCDD/F fingerprint of the boiler and fly ash of an MSW incinerator of the grate furnace type (GFI) described in [16]. In this incinerator it was not possible to sample boiler and fly ash separately, so only the fingerprint of the mixed ash sample is given. Analysis of the boiler and fly ash of the GFI was performed during the same measuring campaign as for the RKI, applying exactly the same analytical techniques. The fingerprint of the GFI, incinerating MSW with a low PCB concentration, is given for reasons of comparison i.e. to better illustrate the influence of a high PCB and chlorinated pesticide concentration in the hazardous waste on the PCDD/F formation mechanism. The total PCDD/F concentration in the boiler and the fly ash of the RKI was 7,180 and $24,132 \mathrm{ng} \mathrm{kg}^{-1}$, respectively. The total PCDD/F concentration in the boiler and fly ash of the GFI was $6,202 \mathrm{ng} \mathrm{kg}^{-1}$. 


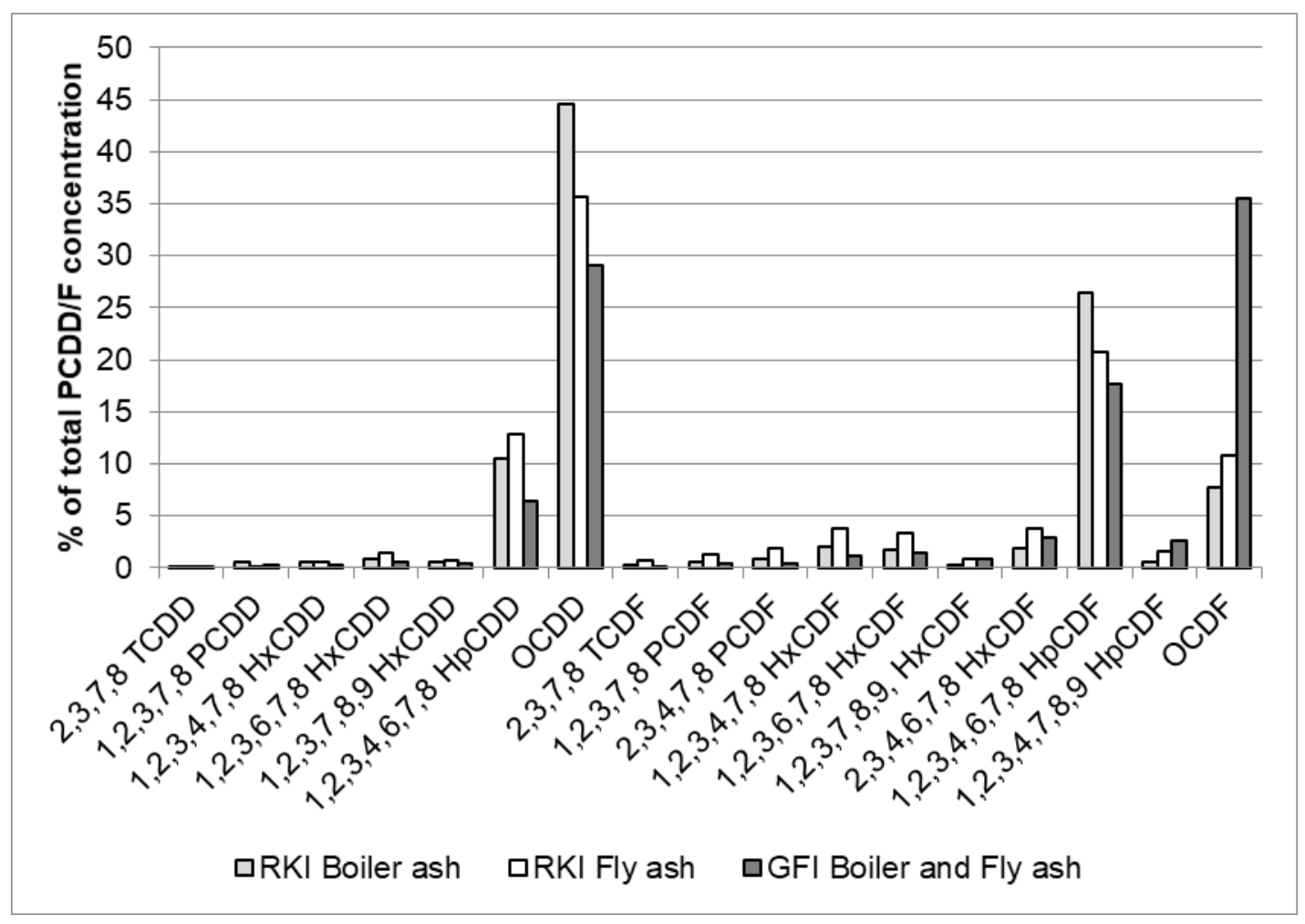

Fig. 2 PCDD/F fingerprints of the boiler and fly ash of the RKI incinerating hazardous waste and, for reasons of comparison, of the GFI incinerating MSW. The bars indicate the concentrations in the pooled samples.

Table 2 gives the PCDF/PCDD-ratio of the boiler and fly ash of these two incinerators. In order to distinguish between the homogeneous precursor condensation mechanism, which yields more low chlorinated PCDFs, and de novo synthesis, which yields more high chlorinated PCDFs, Table 2 gives separate PCDF/PCDD ratios for the tetra and penta$\mathrm{CDD} / \mathrm{Fs}$ (low chlorinated homologues), and for the hexa to octa-PCDD/Fs (moderate chlorinated homologues). The PCDD/F fingerprint of the boiler and the fly ash RKI (left bars in Fig. 2) is clearly dominated by the high chlorinated homologues, i.e. hepta- and octachlorinated dioxins and furans, indicating that the heterogeneous formation pathways are dominant. Furthermore, the fingerprints, which are very similar, contain more high chlorinated dioxins than furans. This is also reflected in the overall and the high chlorinated PCDF/PCDD-ratios (Table 2) that are less than 1, indicating that heterogeneous precursor 
condensation is the dominant formation mechanism. In contrast, the fingerprint of the GFI (Fig. 2), incinerating MSW, contains more high chlorinated furans than dioxins, which is typical for de novo synthesis. This is also reflected in the overall and the high chlorinated PCDF/PCDD-ratios in Table 2, which exceed 1 for the GFI.

Table 2 PCDF/PCDD-ratios of the boiler and fly ash and PCB concentration in the input of the RKI and, for reasons of comparison, of a GFI

\begin{tabular}{|l|c|c|c|c|}
\hline Incinerator & \multicolumn{3}{|c|}{ PCDF/PCDD-ratio } & $\begin{array}{l}\text { PCB concentration in } \\
\text { waste input [\%] }\end{array}$ \\
\hline & Overall & $\begin{array}{c}\text { Moderate } \\
\text { chlorinated } \\
\text { homologues }\end{array}$ & $\begin{array}{c}\text { High chlorinated } \\
\text { homologues }\end{array}$ & \\
\hline RKI Boiler ash & 0.73 & 2.92 & 0.71 & $1.50^{\mathrm{a}}$ \\
\hline RKI Fly ash & 0.95 & 22 & 0.87 & $1.50^{\mathrm{a}}$ \\
\hline GFI & 1.71 & 3.53 & 1.69 & $2.110^{-6 \mathrm{~b}}$ \\
\hline
\end{tabular}

${ }^{\mathrm{a}}$ Concentration of PCBs and chlorinated POP pesticides [14]

${ }^{\mathrm{b}}$ Average of PCB concentrations reported in [14]

Huang and Buekens [2] stated that the heterogeneous precursor pathway could become predominant only for precursor concentrations 5-6 orders of magnitude higher than those generally encountered in raw combustion gases of MSW incinerators. Remarkably, the concentration of PCBs and chlorinated POP pesticides in the waste input of the RKI is also 56 orders of magnitude higher than in MSW [14]. Indeed, the fact that heterogeneous precursor condensation is the dominant $\mathrm{PCDD} / \mathrm{F}$ formation mechanism in the $\mathrm{RKI}$ indicates that the concentration of precursors in the combustion gas in the boiler and ESP of this incinerator is higher than in MSW incinerators where de novo synthesis is the dominant PCDD/F formation mechanism. PCDD/F precursors are products of incomplete combustion of PCBs and of some types of chlorinated pesticides e.g. DDT and hexachlorobenzene, and of certain non-chlorinated hydrocarbons such as cellulose and lignin, which are in principle the 
main source of precursors in MSW. PCBs and chlorinated pesticides, present in high concentrations in the waste input of the RKI, require longer residence times at elevated temperatures for decomposition than cellulose and lignin [17-18] because the carbon-chlorine bond is much stronger than the carbon-carbon bond. So it is to be expected that in waste incinerators cellulose and lignin are completely thermally destroyed in the furnace and do not yield PCDD/F precursors in the combustion gas. So PCDD/F precursors mainly originate from incomplete combustion of PCBs and chlorinated pesticides. Since the concentration of these substances is much higher in the waste input of the RKI, this explains their higher concentration in the post combustion zone and the dominance of the precursor condensation formation mechanism.

Previous results [12] have confirmed that a smaller increase of PCBs in the input waste mix of a fluidized bed combustor (i.e. up to 2 orders of magnitude due to co-combustion of automotive shredder residue) did not result in a change of PCDD/F formation mechanism, de novo synthesis remaining the dominant pathway.

Tetra- and penta-CDD/Fs (low chlorinated homologues) account for up to $4 \%$ of the total PCDD/F concentration in the boiler and fly ash of the RKI. Table 2 indicates that the PCDF/PCDD-ratio of the low chlorinated homologues is much higher for the RKI than for the GFI. As low chlorinated furans are preferentially formed by homogeneous precursor condensation, this indicates that the higher precursor concentration in the RKI not only increases the formation rate of heterogeneous precursor condensation, but, as expected, also increases that of homogeneous precursor condensation.

\section{Conclusions and recommendations for further research}

The fingerprint of the 17 PCDD/Fs with TEF values of the boiler and fly ash of a hazardous waste incinerator inidates that, if the PCB concentration in the waste to be incinerated is $10^{5}-$ $10^{6}$ times higher than in MSW, heterogeneous precursor condensation becomes the dominant 
$\mathrm{PCDD} / \mathrm{F}$ formation mechanism rather than de novo synthesis. This conclusion is based on a limited dataset. In order to further corroborate this conclusion, a more complete congener pattern for mono-octachlorinated CDD/Fs should be obtained. Furthermore, the concentration of precursor molecules such as chlorinated phenols and benzenes should be determined in the combustion gas. This was however not possible in the framework of this study.

\section{Acknowledgements}

Andres Van Brecht, Guido Wauters and Pieter Van Royen from Indaver NV are acknowledged for their kind collaboration and support with the data gathering for this study.

\section{References}

[1] Hites R (2011) Dioxins: An overview and history. Environ Sci Technol 45:16-20

[2] Huang H, Buekens A (1995) On the mechanisms of dioxin formation in combustion processes. Chemosphere 31:4099-4117

[3] Stanmore BR (2004) The formation of dioxins in combustion systems. Combust Flame 136: $398-427$

[4] Altarawneh M, Dlugogorski BZ, Kennedy EM, Mackie JC (2009) Mechanisms for formation, chlorination, dechlorination and destruction of polychlorinated dibenzo-p-dioxins and dibenzofurans (PCDD/Fs). Prog Energy Combust Sci 35:245-274

[5] Nakahata DT, Mulholland JA (2000) Effect of dichlorophenol substitution pattern on furan and dioxin formation. Proc Combust Inst 28:2701-2707

[6] Wikström E, Ryan S, Touati A, Tabor D, Gullett BK (2004) Origin of carbon in polychlorinated dioxins and furans formed during sooting combustion. Environ Sci Technol $38: 3778-3784$

[7] Wikström E, Ryan S, Touati A, Gullett BK (2004) In situ formed soot deposit as a carbon source for polychlorinated dibenzo-p-dioxins and dibenzofurans. Environ Sci Technol 38:2097-2101 
[8] Ryu J Y, Choi KC, Mulholland JA (2006) Polychlorinated dibenzo-p-dioxin (PCDD) and dibenzofuran (PCDF) isomer pattern from municipal waste combustion: Formation mechanism fingerprints. Chemosphere 65:1526-1536

[9] Khachatryan L, Burcat A, Dellinger B (2003) An elementary reaction-kinetic model for the gas-phase formation of 1,3,6,8- and 1,3,7,9-tetrachlorinated dibenzo-p-dioxins from 2,4,6-trichlorophenol. Combust Flame 132: 406-421

[10] Abad E, Caixach J, Rivera J (2003) Improvements in dioxin abatement strategies at a municipal waste management plant in Barcelona. Chemosphere 50:1175-1182 [11] Van Caneghem J, Block C, Vermeulen I, Van Brecht A, Van Royen P, Jaspers M, Wauters G, Vandecasteele C (2010) Mass balance for POPs in a real scale fluidised bed combustor co-incinerating automotive shredder residue. J Hazard Mater 181:827-835 [12] Van Caneghem J, Block C, Vermeulen I, Van Brecht A, Van Royen P, Jaspers M, Wauters G, Vandecasteele C (2012) Destruction and formation of PCDD/Fs in a fluidized bed combustor co-incinerating automotive shredder residue with refuse derived fuel and waste water treatment sludge. J Hazard Mater 207-208:152-158

[13] Zhang G, Hai J, Cheng J (2012) Characterisation and mass balance of dioxin from large scale municipal solid waste incinerator in China. Waste Manage 32:1156 -1162 [14] Van Caneghem J, Block C, Van Brecht A, Wauters G, Vandecasteele C (2010) Mass balance for POPs in hazardous and municipal waste incinerators. Chemosphere 78:701-708 [15] Bundesministerium fur Umwelt, Naturschutz und Reaktorsicherheit (2006) Ordinance on Waste and Sewage Sludge (AbfklärV). Annex 1: Sampling, sample preparation and analysis of sludge and soil

[16] Vandecasteele C, Wauters G, Arickx S, Jaspers M, Van Gerven T (2007) Integrated municipal solid waste treatment using a grate furnace incinerator: The Indaver case. Waste Manage 27:1366-1375. 
[17] Gupta AK (1986) Combustion of chlorinated hydrocarbons. Chem Eng Comun 41: 1-21

[18] Ravindran V, Pirbazari M, Benson SW, Badriyha BN, Evans DH (1997) Thermal destruction of chlorinated hydrocarbons by reductive pyrolysis. Combust Sci and Tech 122: $183-213$ 


\section{$\underline{\text { Figure captions }}$}

Fig. 1 Schematic overview of the rotary kiln incinerator (RKI) with indication of sampling points and temperatures in post combustion zone

Fig. 2 PCDD/F fingerprints of the boiler and fly ash of the RKI incinerating hazardous waste and, for reasons of comparison, of the GFI incinerating MSW. The bars indicate the concentrations in the pooled samples. 